\title{
The Association Between Social Media Use and Hazardous Alcohol Use Among Youths : A Four-Country Study
}

\section{Savolainen, lina}

2020-01

Savolainen , I , Oksanen , A , Kaakinen , M , Sirola , A, Miller , B L , Paek , H-J \& Zych , I 2020 , ' The Association Between Social Media Use and Hazardous Alcohol Use Among

Youths : A Four-Country Study ' , Alcohol \& Alcoholism , vol. 55 , no. 1, pp. 86-95 . https://doi.org/10.1093/alcalc/agz

http://hdl.handle.net/10138/339422

https://doi.org/10.1093/alcalc/agz088

unspecified

acceptedVersion

Downloaded from Helda, University of Helsinki institutional repository.

This is an electronic reprint of the original article.

This reprint may differ from the original in pagination and typographic detail.

Please cite the original version. 
This is the accepted manuscript of the article, which has been published in

Alcohol and Alcoholism. https://doi.org/10.1093/alcalc/agz088

Iina Savolainen, Atte Oksanen, Markus Kaakinen, Anu Sirola, Bryan Lee Miller, Hye-Jin Paek, Izabela Zych

Running head: Social Media and hazardous alcohol use

\title{
The association between social media use and hazardous alcohol use among youths: A four-country study
}

\begin{abstract}
Background: Youths are susceptible to peer influence and behaviour models set by others. Since the emergence of social media, young individuals have adapted and been active users of its many platforms. Correspondingly, social influence and behavioural diffusion are now taking place through the virtual world. This has been connected to the spread of different risk behaviours, including youth hazardous alcohol consumption. This study examines the continuing role of daily popular social media use in youth hazardous alcohol consumption in four countries across continents. Method: A web-based survey was given to youths aged 15-25 in the United States $(n=1,212)$, South Korea $(n=1,192)$, Finland $(n=1,200)$, and Spain $(n=1,212)$. Hazardous alcohol use (AUDIT-C) was the dependent variable. Main independent variables measured daily use of different social media services. Controls included compulsive Internet use, offline belonging, psychological distress, impulsivity, risk-taking, age, and gender. Linear regression models and
\end{abstract}


mediation analyses with bootstrapping were done for each country. Results: Daily usage of either Facebook, Instagram or instant messaging was associated with hazardous alcohol use among youths, though variations between effect sizes and countries existed. Differing relationships were observed in hazardous drinking and daily YouTube and Twitter use. The mediation analyses revealed that uploading pictures to social media is a possible facilitator of social media-related hazardous alcohol use among youths in the U.S. and Spain. Discussion: Results help form a better understanding on which type of social media platforms may inspire youth or attract hazardously drinking youths, contributing to the growing opportunities for social media interventions.

Keywords: youth behaviour, social media, hazardous alcohol use, cross-country comparison

\section{Summary}

This four-country study examines daily social media use and its association with youth hazardous alcohol consumption. Results indicate that daily use of user-oriented social media is a significant predictor of high hazardous alcohol use among youth across countries. Uploading pictures to social media may facilitate social media-related hazardous alcohol use. 
The association between daily social media use and hazardous alcohol use among youths:

\section{A four-country study}

Social media and different social networking sites have become popular over the last decade. In particular, emerging adults (18 to 24-year-olds) stand out in the ways they consume social media (Anderson and Jiang, 2018a; Smith and Anderson, 2018) and, as members of a generation who grew up with modern technological advancements, the majority of them are technologically savvy. Since the emergence of the first social media platforms (e.g., MSN Messenger, MySpace, and Facebook), numerous new services have joined the market and offered faster, more efficient, and sophisticated ways of communicating and sharing content.

According to the Pew Research Center, Americans aged 18 to 24 embrace various platforms and use them frequently. However, this age group is considerably more likely to use platforms such as Snapchat, Instagram, and Twitter when compared to individuals aged 25 years and older, who are more likely to use Facebook. Half of the emerging adult social media users report it would be difficult for them to give up social media, underlining their value in young individuals' life (Smith and Anderson, 2018). The most popular online platforms among teens from 13 to 17 years old are YouTube, Instagram, and Snapchat. Altogether, 95\% of American teens have access to a smartphone, and 45\% report they are online 'almost constantly' (Anderson and Jiang, 2018b). Similar trends in social media use and smart phone access are recognized across countries. For instance, in Finland, 93\% of 16 to 24-year olds use social media and nearly all of them have access to a smartphone (Official Statistics of Finland, 2017).

Social media platforms offer many benefits and they serve multiple roles in people's everyday life: they are forums for sharing and accessing information and news, keeping in touch with family and friends, and networking with different communities (Barker, 2009; Holt et al., 
2013; Boyd, 2014; Boulianne, 2015). Social media platforms are typically classified into two broad categories: user-oriented and content-oriented (Pallis et al., 2011; Yoo et al., 2018). User-oriented social media, such as Facebook or Instagram, are based on people’s relationships and content is mainly shared among users. In these types of social media, users typically have a visible identity. Content-oriented social media like YouTube or Twitter, establish networks around users' shared interests. In these types of platforms, people are mostly anonymous (Pallis et al., 2011; Yoo et al., 2018).

Routine use of social media is beneficial for young people, as it enhances communication and technical skills, increases learning opportunities and information seeking, as well as extends individuals’ social connections (O'Keeffe and Clarke-Pearson, 2011). The consequences of social media use, however, are not all positive and using digital media can become risky, even dangerous, in many ways (Herr, 2007; Keipi et al., 2017). Past research has connected active youth social media use to harmful phenomena, such as cyberbullying and online hate (Ybarra and Mitchell, 2008; Oksanen et al., 2014; Whittaker and Kowalski, 2015; Kaakinen et al., 2018), sexting (i.e., sending, receiving, and forwarding content or images that are sexually implicit; Hasinoff, 2013), and violence (Patton et al., 2014).

Given the vast amount of content that spreads around social media, it seems inevitable that young individuals encounter harmful online content at some point. Much of this content is inherently related to alcohol and alcohol use, and influenced by alcohol marketing (Winpenny et al., 2013; Hoffman et al., 2014). By examining alcohol marketing in social media, past research has consistently shown a relation between youth social media use and increased alcohol consumption (Griffiths and Casswell, 2010; McCreanor et al., 2013; Jernigan and Rushman, 2014).

Although countries aim to regulate alcohol marketing in different ways, sophisticated advertisements and promotions of alcohol are visible on social media and other communication channels (WHO, 2010). Indeed, regulating alcohol marketing or otherwise alcohol-related content 
on social media has proven difficult (Nicholls, 2012). Different regulatory agencies, such as the Tobacco Tax and Trade Bureau in the United States or the Audiovisual Media Services Directive in Europe, in association with alcohol health campaigners, aim to raise awareness and reduce alcohol related harms through different media (European Centre for Monitoring Alcohol Marketing [EUCAM] 2018; Tobacco Tax and Trade Bureau, 2018). However, they struggle to keep pace with advertising and content that takes place in the dynamic social media environment that changes rapidly (Nicholls, 2012; EUCAM, 2018).

Youth also generate alcohol-related content themselves and share these related experiences, images, and messages on their social media sites. One study found that out of a sample of 400 young users' online platform profiles, more than half (56\%) contained references to alcohol use, frequently displaying motivating use of alcohol (Moreno et al., 2010). A recent meta-analysis by Curtis and colleagues (2018) concluded that among adolescents and young adults, exposure to substance use content in social media, as well as alcohol-related social media engagement were associated with higher self-reported drinking and alcohol problems. It is possible that social influence and behavioural diffusion (i.e., imitation through social learning; Bandura, 1977) take place through social media, thus, contributing to the spread of hazardous alcohol use among those young individuals who encounter alcohol-related content and who are susceptible to social influence.

Adolescents and especially emerging adults are in transition towards adulthood. They are more likely to explore identities, lifestyles, and new habits (Arnett, 2000). Eventually, they are also more likely to engage in risky behaviours and succumb to peer pressure, leading to problems (Arnett, 2005; Blokland et al., 2005; Fergus et al., 2007; Oksanen et al., 2017). Much of these predispositions are credited to their higher impulsivity and risk-taking tendencies (Romer, 2010; Romer et al., 2011; Blakemore and Robbins, 2012; Fernie et al., 2013), related to immature brain development (Berns et al., 2009; Arain, 2013). Even though adolescents and young adults are 
insightful and have enormous potential to learn (Larson and Hansen, 2005), many engage in problem behaviours, including hazardous alcohol consumption (i.e., a pattern of alcohol consumption that includes a risk of detrimental consequences to the drinker [Babor and HigginsBiddle, 2001]). Past research has linked impulsivity and risk-taking tendencies to both social media use and increased drinking (Fernie et al., 2013; Wu et al., 2013; Patrick and Schulenberg, 2014; Richards et al., 2015).

In 2016, 9\% of adolescents and 57\% of young adults consumed alcohol in the past month in the United States (SAMHSA, 2018). Hazardous drinking of alcohol in any age group is a serious public health concern, but the risks heighten among young people, as they undergo important developmental stages (Plant, 2002). As past research shows, alcohol can impact brain development among adolescents, lead to risky behaviours, accidents, infectious diseases, or even death (Plant, 2002; McMorris et al., 2011; Hallgren et al., 2012; NIHAAA, 2017).

Research has established a strong relationship between youth social media and alcohol use, but little research has focused on this association by separating different types of social media or possible features of social media that could help further explain this relationship. The current research aims to fulfil this research gap and provide additional exploration of the relationship between social media use and youth alcohol consumption, while controlling for possible complex superseding variables: compulsive Internet use, psychological distress, offline belonging, impulsivity, and risk-taking tendencies.

In effort to distinguish daily social media use from active Internet use in general, compulsive Internet use is accounted for. Additionally, compulsive or otherwise excessive Internet use has been associated with other harmful behaviours, including alcohol use (Mei et al., 2016; Morioka et al., 2017). High Internet use is also correlated with mental health problems, such as loneliness and depression (Bener and Bhugra, 2013; Gamez, 2014; Ciarrochi et al., 2016), negatively impacting psychological wellbeing (Van den Eijnden et al., 2008; Fioravanti et al., 2012; 
Best et al., 2014). Research on youth alcohol use, instead, has established a relationship between heavy alcohol use and lower psychological wellbeing (e.g., Wills et al., 1996; Chassin et al., 2002; Schulenberg and Maggs, 2002). On the other hand, young individuals who share similar drinking patterns perceive their friendships higher in quality, even if drinking is problematic (Stogner et al., 2015). These offline friendships may further influence youth drinking patterns (McGloin, 2009; Boman et al., 2013). Moreover, youth who have strong offline social relationships are better protected from the negative impact of harmful online content (Minkkinen et al., 2016; Kaakinen et al., 2018).

This research examines the relationship between youth hazardous alcohol use and different types of popular social media use in four countries: The United States, South Korea, Finland, and Spain. To extend our understanding of additional elements of social media that might contribute to this relationship, we investigate whether the positive association between social media use and hazardous alcohol use is mediated by the tendency to share pictures of oneself on social media (Steers et al., 2019). The rationale for this possible mediating relationship lies in reciprocity: content is shared for other users to view and react to, which is a central element of social media. Sharing pictures online is a form of communication driven by social needs, and viewing and sharing photos often occur in tandem (Oeldorf-Hirsch and Sundar, 2016). Active users who upload pictures and post content frequently are also more active in interacting online and viewing and reacting to others' images. This could increase the amount of alcohol-related discussions, content, and imagery circulating in social media and over-inflate drinking norms (Steers et al., 2019). Consequently, exposure to alcohol-related user-content may contribute to young users' hazardous alcohol consumption (Boyle et al., 2016; Erevik et al., 2018).

Our cross-national sample consists of technologically advanced countries in which youth engage in social media use to a similar extent (Anderson and Jiang, 2018; Statista, 2017, 2018a, 2018b, 2019) and allows for testing whether the hypothesized relationships between social media 
and hazardous alcohol use can be observed across diverse cultural contexts. Given the cultural diversity of these countries (Western vs. Eastern, Nordic vs. Southern European) they offer interesting comparisons when observing social media related youth alcohol use.

\section{Method}

\section{Participants}

The participants were 15-25-year-old adolescents and young adults who entered the study from the United States $\left(n=1212,50.17 \%\right.$ female, $\left.M_{\text {age }}=20.05, \mathrm{SD}_{\mathrm{age}}=3.19\right)$ in January 2018, South Korea ( $n=1192,50.42 \%$ female, $\left.\mathrm{M}_{\mathrm{age}}=20.61, \mathrm{SD}_{\mathrm{age}}=3.24\right)$ in February 2018, Finland $(n=1200,50 \%$ female, Mage=21.29, SDage=2.85) in March-April 2017, and Spain ( $n=1212,48.76 \%$ female, $\mathrm{M}_{\text {age }}=20.07, \mathrm{SD}_{\mathrm{age}}=3.16$ ) in January 2019. In order to achieve data that mirrored the current population estimates of each examined country, the data were demographically balanced for age, gender, and living area in all four countries.

\section{Procedure}

Data collection was established by employing comprehensive web-based surveys. The participants were recruited from a volunteer participant pool administered by Dynata (formerly known as Survey Sampling International). The survey was designed in Finnish and in English. The survey consists of previously validated measures that have been widely used in comparative research. The accuracy and comparability of other items were guaranteed by the back-translation process. In 2018, the data collection expanded to South Korea and Spain, where proficient native Korean and Spanish speakers translated the English survey into Korean and Spanish. These surveys went through the back-translation procedures to assure the survey was internally consistent and the items matched accurately. 


\section{Measures}

Hazardous alcohol use. The Alcohol Use Disorders Identification Test (AUDIT-C) was used to measure hazardous alcohol use. The measure includes three questions about alcohol consumption: (1) “How often do you have a drink containing alcohol?” (2) “How many drinks containing alcohol do you have on a typical day when you are drinking?” and (3) “How often do you have six or more drinks on one occasion?” Each question brings 0-4 risk points. The measure is validated for several populations and provides a reliable and quick way to identify individuals with hazardous drinking habits (Bush et al., 1998; Rubinsky et al., 2013). The measure had good internal consistency ( $\alpha=$ .87 in the U.S., $\alpha=.80$ in South Korea, $\alpha=.82$ in Finland, and $\alpha=.81$ in Spain). The measure was used as a continuous variable in our main analyses. For additional logistic analyses, we dichotomized the variable using a cut-off score of $\geq 3$ (Knight et al., 2003; de Meneses-Gaya et al., 2009).

Daily social media use was screened with the question: "How often do you use the following online sites and services?” The online platforms listed in the question were widespread and included Facebook, YouTube, Twitter, Periscope, Instagram, online dating services (e.g., Tinder), instant messaging (e.g., WhatsApp, Snapchat), entertainment streaming services (e.g., Netflix, Amazon video), news sites, general discussion forums, online gaming sites and communities, dark web, online casino sites, and online gambling forums or gambling communities. Answers were provided on a scale ranging from 0 to 3 ( $0=$ I don't use, $1=$ Seldom, $2=$ Daily, $3=$ Several times a day). Out of all the social media services screened, five were chosen for the study analyses on the basis of their global popularity, type of orientation, and functional capabilities. The social media services included in the analyses were: Facebook, YouTube, Twitter, Instagram, and Instant messaging. Each response scale was recoded into a dummy variable in order to separate the daily users from the less active social media users ( 0 = non-daily user, $1=$ daily user $)$. 
Uploading pictures was measured with the question "How often do you upload pictures of yourself into social media?” Answers were provided on a Likert scale ranging from 0 (never) to 7 (daily). In order to distinguish those who upload pictures of themselves to social media frequently, the variable was dichotomized $(0=$ never, $1=$ frequently). The variable was treated as a mediator in our binary mediation analysis.

Compulsive Internet Use was measured with the Compulsive Internet Use scale (CIUS). The scale consists of 14 items, which target the consequences and states of mind related to Internet use (Meerkerk et al, 2009; Lopez-Fernandez et al., 2019). The scale has good psychometric properties. Responses range on a five-point scale from 0 (never) to 4 (very often), with a higher score indicating compulsive Internet use. The scale had excellent internal consistency ( $\alpha=.95$ in the U.S., $\alpha=.94$ in South Korea, $\alpha=.94$ in Finland, and $\alpha=.93$ in Spain).

Offline belonging. To measure and account for the participants’ social disposition, we employed the question “How strongly do you feel you belong to the following?” Items included “family,” “friendship group,” and “school or work community”. Strength of belonging was indicated on a scale from 1 (not at all) to 10 (very strongly). The variable was turned into a sumcomposite.

Impulsivity. The Eysenck Impulsivity Scale (Eysenck and Eysenck, 1977) was used to measure impulsive behaviour patterns. The measure consisted of five items each targeting different aspects of impulsive behaviour. Answer options were dichotomous $(1=y e s, 0=n o)$ and the range of the scale varies from 0 to 5. The scale has good psychometric properties (MacKillop et al., 2006) and it is widely used in research studies examining the role of impulsivity in different problem behaviours (Auger et al., 2010; Dussault et al., 2011). Cronbach’s alpha coefficients for the scale were .69 in the U.S., .63 in South Korea, .74 in Finland, and .66 in Spain.

Psychological distress. The General Health Questionnaire, GHQ-12 (Goldberg et al., 1997; Pevalin, 2000) was used to measure psychological distress. The questionnaire is extensively used in 
mental health research when assessing mental well-being and screening for individuals' likelihood of having, or being at risk of developing, a psychiatric disorder. The measure is designed to detect common mental health problems, such as depression, anxiety, and social withdrawal (Werneke et al., 2000). A total of 12 questions with a 4-point scale $(0=$ better than usual, $3=$ much less than usual) screen for psychological well-being. A higher score indicates higher psychological distress. The scale has good internal consistency ( $\alpha=.88$ in the U.S., $\alpha=.86$ in South Korea, $\alpha=.88$ in Finland, $\alpha=.86$ in Spain) and reliability.

Risk-taking. A single-item measure was utilized to screen for risk-taking tendencies. The item stated "I enjoy taking risks" to which the participants were asked to provide an answer on a scale from 1 (Not very true of me) to 10 (Very true of me). The item was drawn from the National Longitudinal Survey of Youth -79 and has been determined a valid measure for risk-taking behaviours (Hawdon et al., 2018; Savimäki et al., 2018).

\section{Statistical Analysis}

Stata 15.1 software was used to analyse the relationship between daily use of different types of social media and hazardous alcohol use. Descriptive statistics are provided for all target variables as means $(M)$ and standard deviations $(S D)$ for continuous variables and as frequencies (n) and relational proportions (\%) for categorical variables (Table 1). We conducted a linear regression analysis for daily social media use and the AUDIT-C sum variable. The assumptions of OLS regression were met, but due to heteroscedasticity of the residuals, we ran the models using HuberWhite standard errors (i.e., robust standard errors). Analyses were run separately for each social media type to observe possible differences between distinctive forms of social media and their relationship to hazardous alcohol consumption. Individual analyses were conducted for each country to accurately compare the observed effects (Table 2). 
We also tested our regression models separately for two age groups: those between 15 to 17 years old and those between 18 to 25 years old. Alternative logistic regression analyses were run to observe the results for those young people whose drinking behaviour was classified as hazardous (received $\geq 3$ on the AUDIT-C [Knight et al., 2003; de Meneses-Gaya et al., 2009]). These results are provided in the Appendix (Table 3).

An additional binary mediation analysis with a 2,000-replication bootstrap was conducted to examine whether the relationship between daily social media use and hazardous alcohol consumption is mediated by pictures young individuals upload of themselves to their social media accounts. The binary mediation analyses were conducted for daily Facebook use and daily Instagram use only. These two social media platforms were chosen for additional analysis due to their global popularity, and because they represent user-oriented social media, where users interact socially, as well as create and share content (Yoo et al., 2018). Thus, Facebook and Instagram exemplify platforms through which users most typically upload and share pictures with others.

\section{Results}

Descriptive statistics showed that the mean hazardous alcohol use score (AUDIT-C) was highest in Finland, followed by South Korea, Spain, and the U.S. Our multivariate analyses discovered that hazardous alcohol use and daily social media use were related in distinctive ways, depending on the social media service used. Daily use of Facebook was a significant predictor of higher hazardous alcohol use in three countries: Finland, South Korea, and Spain. A statistically significant association was also found in the U.S. when adjusting for all controls, except for offline belonging $(B=.26, P=.032)$, but the final model lacked statistical significance $(B=.23, P=.070)$. Daily use of YouTube was related to lower hazardous alcohol use in the United States and Finland. In South Korea, daily use of YouTube was related to higher hazardous alcohol use. No relationship was observed in the Spanish sample. Daily use of Twitter was associated with higher hazardous alcohol 
use among the Spanish sample. Among the Finnish sample, daily Twitter use was related to lower hazardous alcohol use. In South Korea and the U.S., no significant association between daily Twitter use and hazardous alcohol use was observed.

Daily Instagram use was associated with higher hazardous alcohol use in South Korea, Finland, and Spain. In the U.S., daily Instagram use did not predict hazardous alcohol use. Daily instant messaging was a significant predictor of higher hazardous alcohol use in Finland and South Korea.

As an additional investigation, we ran the analyses separately for two age groups: those between 15 to 17 years old and those between 18 to 25 years old (these results not reported in tables). In the U.S., daily YouTube use was associated with lower hazardous drinking only among the 18 to 25 age group $(B=-.44, P=.005)$. In South Korea, daily use of Facebook, YouTube, Instagram, and instant messaging were associated with higher hazardous alcohol use only among the 18 to 25 age group $(B=1.4, P<.001 ; B=.71, P=.001 ; B=1.1, P<.001 ; B=.99, P<.001$, respectively). In Finland, daily use of Facebook, Instagram, and instant messaging were associated with higher hazardous alcohol use only among the 18 to 25 age group $(B=.53, P=.001 ; B=.39, P$ $=.026 ; B=.68, P<.001$, respectively). Also, among Finnish 18-25-year olds, daily YouTube use was associated with lower hazardous alcohol use $(B=-.52, P=.002)$ and daily Instagram use was associated with higher hazardous alcohol use $(B=.30, P=.034)$.

According to our mediation tests (Figure 1), the indirect effects between daily Facebook use and higher hazardous alcohol use via uploading pictures to social media were significant in the U.S. $(B=.41, S E=.13,95 \%$ CI $[.15, .68])$ and Spain $(B=.35, S E=.13,95 \%$ CI $[.10, .60])$. The bootstrapped indirect effect of daily Facebook use via uploading pictures to social media was .011, with a 95\% confidence interval [.002, .022] in the U.S. sample and .012 with a 95\% CI [.001, .022] in the Spanish sample. Similarly, the mediation analyses indicated an indirect significant relationship between daily Instagram use and higher hazardous alcohol use via uploading pictures to 
social media among youth in the U.S. $(B=.44, S E=.13,95 \%$ CI $[.17, .70])$ and Spain $(B=.37, S E$ $=.13,95 \%$ CI $[.12, .62])$. The bootstrapped indirect effect of daily Instagram use via uploading pictures to social media was .010 with a 95\% confidence interval $[.001, .018]$ in the U.S. and .010 with a 95\% CI $[.00, .019]$ in Spain. Among the South Korean and Finnish samples, no indirect effects were found in terms of daily Facebook or daily Instagram use and hazardous alcohol use.

\section{Discussion}

This research study examined the relationship between hazardous alcohol use and daily use of popular social media platforms among youth in the U.S., South Korea, Finland, and Spain. By doing so, this study aimed to contribute to the existing literature and respond to the lack of investigation in how different social media may facilitate and enhance alcohol use among youth around the world. Our results revealed that daily Facebook use was consistently associated with higher hazardous alcohol consumption among young individuals in three countries: South Korea, Finland, and Spain, but not directly in the United States. Similarly, daily Instagram use was associated with higher youth hazardous alcohol consumption in South Korea, Finland, and Spain, but no direct effect was observed in the United States. Daily instant messaging was strongly linked to higher youth hazardous drinking in South Korea and Finland.

Daily Twitter use was significantly related to higher hazardous alcohol use in Spain, but this relationship did not remain significant after splitting the sample into smaller age-groups; those under and over 18 years. The direction was similar among the U.S. sample, although the relationship did not remain statistically significant after controlling for compulsive Internet use, offline belonging, psychological distress, impulsivity, risk-taking, age, and gender. In Finland, daily Twitter use was related to lower hazardous alcohol use. Daily YouTube use was associated with lower hazardous alcohol use among youth in the U.S. and Finland, but higher hazardous alcohol use among youth in South Korea. By investigating these association with two separate age groups, we were able to observe some additional differences between daily social media use and hazardous 
alcohol use. It seems that emerging adults, in particular, are at risk when it comes to active social media use and hazardous drinking. These results might indicate that young adults ( $\geq 18$ years of age) have increased access to alcohol products.

These cross-nationally varying relationships between hazardous alcohol use and types of social media offer an opening for critical interpretation. First and foremost, these results provide insight into the diverse user-cultures that prevail within different social media. While user-oriented social media (Facebook, Instagram, and instant messaging) rely on social interaction among users, and content created and disseminated by users, content-oriented social media (Twitter and YouTube), provide content that can be viewed and navigated by users without anticipated reciprocal interaction (Yoo et al., 2018). It is likely that different platforms attract distinct types of users, creating unique, even polarized, user-groups within them (i.e., those using Facebook or YouTube focus mostly on these platforms for their specific capabilities). Correspondingly, it is possible that youths who are hazardous drinkers prefer certain social media platforms over others due to unique features.

These user-cultures might also explain some of the variation observed in our results across the different countries. While these platforms are used in a similar fashion across the four countries, they might attract very specific types of users depending on the context of the country. For instance, YouTube users in different parts of South Korea might be motivated to use the platform for unique underlying reasons, when compared to youth across different states in the U.S. or areas of Finland. This might also partly explain our nonsignificant direct findings within the U.S. sample. It is possible that populations that are more likely to engage in heavy drinking within the country context, such as college students (Slutske, 2005; Hingson, 2010), utilize platforms like Facebook and Instagram for content generation and sharing, or the gratification received from using them. However, our sample did not capture these individuals specifically. Given the high number of social media users and different patterns of use, these speculations should be made cautiously. 
According to our results, user-oriented social media use is most consistently related to higher youth hazardous alcohol use. This suggests that these types of social media possess some inherent features allowing the association to surface. We propose that one possible feature is behaviour-inspiring imagery, through which the mechanisms of social influence and social learning are relayed. Social media can enable learning experiences in different ways, including by setting examples through images and exchanging experiences (O'Keeffe et al., 2011; Moreno et al., 2013). We also tested this by analysing whether uploading pictures to social media mediates the relationship between daily social media use and hazardous alcohol consumption among young individuals. This was the case in two of the countries examined: the U.S. and Spain. Social networking and social media are undeniably pleasurable and positive aspects in young people's life (McCreanor et al., 2013), but they do seem to create environments that are alcohol-promoting and thus contribute to youth hazardous drinking. Consequently, social media can function as behaviourchanging agents for young individuals.

It is reasonable that youth who party and engage in drinking, and then post related images to social media, are not doing so because of social media, but for other underlying reasons. However, user-oriented social media in particular allows the drinking and partying posts to be disseminated to wide audiences and, thus, are likely to influence and further spread youth drinking behaviour among other youths encountering the content. Furthermore, content encountered in user-oriented social media is typically created and disseminated by the user's own pre-known offline contacts (friends, family, acquaintances, etc.) which may increase the impact and meaning the content has on the user. Content viewed in content-oriented social media, on the other hand, is most commonly created by individuals outside the user's own offline networks or otherwise unknown to the user.

Content-oriented social media (e.g., YouTube) might be a safer type of social media in general; it allows users to search and view specific topics and content that are of interest to them (e.g., hobbies, product information, politics, etc.; Yoo et al., 2018). In the stream of user-oriented 
social media, the user cannot as accurately determine and choose what type of content she or he encounters. Our findings further suggest that different platforms attract and circulate different type of behaviour-influencing content (Kaplan and Haenlein, 2010; Murthy, 2012; Fuchs, 2017). Given their limited self-regulation capacity and susceptibility to social influence (O’Keeffe and ClarkePearson, 2011), we argue that young individuals are at risk of adopting alcohol-use behaviour if they see images, messages or circulating challenges in which alcohol is consumed or promoted in a socially desirable way. To some extent, the findings mirror prior research findings showing that active social media use is associated with youth alcohol consumption (e.g., Ali and Dwyer, 2010; Rosenquist et al., 2010; Moreno and Whitehill, 2014; Hoffman et al., 2016).

Some study limitations should be acknowledged. Even with robust cross-national samples, our study was a cross-sectional survey, so causal interpretations cannot be made. In addition, our data are based on self-reported surveys, which are sensitive to social desirability bias. A further limitation is the lack of objective measures of social media use and exposure to alcohol-related content, creating a need for future research. The associations found in our study were relatively weak, however, it should be noted that our findings concerning the association between the use of social media services in general (not particularly alcohol-related use) and alcohol consumption were replicated in four different countries. Our mediation analyses were only significant in the U.S. and Spain, which might indicate existing differences among youth cultures in those countries versus their counterparts in South Korea and Finland. Future research should aim to replicate these findings in different settings and examine if a mediation effect can be found.

While the AUDIT-C is a validated and reliable screening tool for risky alcohol consumption, it has some limitations. Past research has called into question the appropriateness of brief screening tools, especially those based on questions of consumption, in effort to detect hazardous alcohol use among young people (McCambridge and Thomas, 2009). Additionally, variability in alcohol use behaviour during younger years, such as higher levels of binge drinking, 
or heavy episodic drinking, during adolescence and college-years, may compromise the predictive value of the tool (Kelly et al., 2009; Barry et al., 2015).

The outcomes of active social media use and youth hazardous alcohol use are complex at best, and more research is needed to better understand the possible causal effects between them. Future qualitative research could provide meaningful and deeper understanding on the aforementioned relationships. Another future direction could examine the perceptions and attitudes young people have towards alcohol-related postings and content. While this study analysed the independent associations between four different social media services and hazardous alcohol use, examining user-oriented and content-oriented social media users as separate groups could be important in future research.

The results of this study help form a better understanding on how and what type of social media platforms may inspire hazardous alcohol use among young individuals or, in contrast, attract those individuals who already are heavy drinkers. The results emphasize a need for more regulatory vigor from the social media sites in effort to limit the amount and spread of pro-alcohol content. These findings also contribute to the growing opportunities for implementing intervention methods within different social media, where adolescent and young adult populations spend much of their time. For instance, user-oriented social media profiles could be assessed for interplay patterns to identify at-risk or hazardously drinking individuals (Moreno and Whitehill, 2014). Analogous to the spread of alcohol-content, health-promotion and prevention messages could be delivered through social media. Intervention methods, such as peer-group interventions, taking place in the virtual context might improve youth engagement in such programs. This could increase the reach and impact of prevention and intervention initiatives. 


\section{References}

Ali MM, Dwyer DS. (2010). Social network effects in alcohol consumption among adolescents. Addict Behav 35: 337-342

Anderson M and Jiang J. (2018a). Teens, social media \& technology 2018, Pew Research Center, viewed 28 April 2019, <https://www.pewinternet.org/2018/05/31/teens-social-mediatechnology-2018/>

Anderson M and Jiang J. (2018b). Teens social media habits and experiences, Pew Research Center, viewed 28 April 2019, <https://www.pewinternet.org/2018/11/28/teens-and-their-experienceson-social-media/>

Arain M, Haque M, Johal L, et al. (2013). Maturation of the adolescent brain. Neuropsychiatr Dis Treat 9: 449.

Arnett JJ. (2000). Emerging adulthood: A theory of development from the late teens through the twenties. Am Psychol 55: 469

Arnett JJ. (2005). The developmental context of substance use in emerging adulthood. $J$ Drug Issues 35: 235-254.

Auger N, Lo E, Cantinotti M, O'loughlin J. (2010). Impulsivity and socio-economic status interact to increase the risk of gambling onset among youth. Addiction 105: 2176-2183.

Babor T and Higgins-Biddle J. (2001). Brief Intervention for Hazardous and Harmful Drinking (AUDIT). A Manual for Use in Primary Care, World Health Organization, viewed 30 April 2019, <https://apps.who.int/iris/handle/10665/67210>

Bandura A and Walters RH. (1977). Social learning theory (Vol. 1). Englewood Cliffs, NJ: Prentice-hall.

Barker V. (2009). Older adolescents' motivations for social network site use: The influence of gender, group identity, and collective self-esteem. Cyberpsychol Behav 12: 209-213.

Barry AE, Chaney BH, Stellefson ML, Dodd V. (2015). Evaluating the psychometric properties of 
the AUDIT-C among college students. J Subst Use 20: 1-5.

Bener A and Bhugra D. (2013). Lifestyle and depressive risk factors associated with problematic Internet use in adolescents in an Arabian gulf culture. J Addict Med 7: 236-242.

Berns GS, Moore S, Capra CM. (2009). Adolescent engagement in dangerous behaviors is associated with increased white matter maturity of frontal cortex. PloS One 4: e6773.

Best P, Manktelow R, Taylor B. (2014). Online communication, social media and adolescent wellbeing: A systematic narrative review. Child Youth Serv Rev 41: 27-36.

Blakemore SJ and Robbins TW. (2012). Decision-making in the adolescent brain. Nat Neurosci 15: 1184

Blokland AA, Nagin D, Nieuwbeerta P. (2005). Life span offending trajectories of a Dutch conviction cohort. Criminology 43: 919-954.

Boman IV JH, Stogner J, Lee Miller B. (2013). Binge drinking, marijuana use, and friendships: The relationship between similar and dissimilar usage and friendship quality. $J$ Psychoactive Drugs 45: 218-226.

Boulianne S. (2015). Social media use and participation: a meta-analysis of current research. Inf Commun Soc 18: 524-538

Boyd D. (2014). It's complicated: The social lives of networked teens. Yale University Press. Boyle SC, LaBrie JW, Froidevaux NM, Witkovic YD. (2016). Different digital paths to the keg? How exposure to peers' alcohol-related social media content influences drinking among male and female first-year college students. Addict Behav 57: 21-29.

Bush K, Kivlahan DR, McDonell MB, Fihn SD., Bradley KA. (1998). The AUDIT alcohol consumption questions (AUDIT-C): An effective brief screening test for problem drinking. Arch Intern Med 158: 1789-1795. 
Chassin L, Pitts SC, Prost J. (2002). Binge drinking trajectories from adolescence to emerging adulthood in a high-risk sample: predictors and substance abuse outcomes. $J$ Consult Clin Psychol 70: 67-78.

Ciarrochi J, Parker P, Sahdra B, Marshall S, Jackson C, Gloster AT, Heaven P. (2016). The development of compulsive internet use and mental health: A four-year study of adolescence. Dev Psychol 52: 272.

Curtis BL, Lookatch SJ, Ramo DE, et al. (2018). Meta-Analysis of the Association of AlcoholRelated Social Media Use with Alcohol Consumption and Alcohol-Related Problems in Adolescents and Young Adults. Alcohol Clin Exp Res 42: 978-986.

Erevik EK, Pallesen S, Andreassen CS, Vedaa Ø, Torsheim T. (2018). Who is watching usergenerated alcohol posts on social media? Addict Behav 78, 131-137.

Eysenck SB and Eysenck HJ. (1977). The place of impulsiveness in a dimensional system of personality description. Br J Soc Clin Psychol 16: 57-68.

Fergus S, Zimmerman MA, Caldwell CH. (2007). Growth trajectories of sexual risk behavior in adolescence and young adulthood. Am J Public Health 97: 1096-1101

Fernie G, Peeters M, Gullo MJ, et al. (2013). Multiple behavioural impulsivity tasks predict prospective alcohol involvement in adolescents. Addiction 108: 1916-1923.

Fioravanti G, Dèttore D, Casale S. (2012). Adolescent Internet addiction: testing the association between self-esteem, the perception of Internet attributes, and preference for online social interactions. Cyberpsychol Behav Soc Netw 15: 318-323

Fuchs C. (2017). Social media: A critical introduction. London: Sage Publications Ltd.

Gamez M. (2014). Depressive symptoms and problematic internet use among adolescents: An analysis of the longitudinal relationships from the cognitive-behavioural model. Cyberpsychol Behav Soc Netw 11: 714-719 
Goldberg DP, Gater R, Sartorius N, et al. (1997). The validity of two versions of the GHQ in the WHO study of mental illness in general health care. Psychol Med 27: 191-197.

Griffiths R and Casswell S. (2010). Intoxigenic digital spaces? Youth, social networking sites and alcohol marketing. Drug Alcohol Rev 29: 525-530.

Hallgren M, Leifman H, Andréasson S. (2012). Drinking less but greater harm: could polarized drinking habits explain the divergence between alcohol consumption and harms among youth? Alcohol Alcohol 47: 581-590.

Hasinoff AA. (2013). Sexting as media production: Rethinking social media and sexuality. New Media Soc 15: 449-465.

Hawdon J, Bernatzky C, Costello M. (2018). Cyber-Routines, Political Attitudes, and Exposure to Violence-Advocating Online Extremism. Soc Forces

Herr J. (2007). Internet entangles college students in a web of loneliness and depression, Truman State University Index, viewed 2 May 2019, <www.trumanindex.com/ 2.10111/internetentangles-collegestudents-in-a-web-of-loneliness-anddepression-1.1462>

Hingson RW. (2010). Focus on: College drinking and related problems: magnitude and prevention of college drinking and related problems. Alcohol Res Health 33:45-54.

Hoffman EW, Pinkleton BE, Weintraub Austin E, Reyes-Velázquez W. (2014). Exploring college students' use of general and alcohol-related social media and their associations with alcoholrelated behaviors. J Am Coll Health, 62: 328-335

Hoffman EW, Austin EW, Pinkleton BE, Austin BW. (2017). An exploration of the associations of alcohol-related social media use and message interpretation outcomes to problem drinking among college students. Health Commun 32: 864-871.

Holt K, Shehata A, Strömbäck J, Ljungberg E. (2013). Age and the effects of news media attention and social media use on political interest and participation: Do social media function as leveller? Eur J Commun 28: 19-34 
Jernigan DH and Rushman AE. (2014). Measuring youth exposure to alcohol marketing on social networking sites: Challenges and prospects. J Public Health Policy 35: 91-104.

Kaakinen M, Keipi T, Oksanen A, Räsänen P. (2018). How Social Capital Associates with Online Hate Victimization. Policy Internet, 10: 302-323.

Kaakinen M, Keipi T, Räsänen P, Oksanen A. (2018). Cybercrime victimization and subjective wellbeing: An examination of the buffering effect hypothesis among adolescents and young adults. Cyberpsychol Behav Soc Netw 21: 129-137

Kaplan AM and Haenlein M. (2010). Users of the world, unite! The challenges and opportunities of Social Media. Bus Horiz, 53: 59-68.

Keipi T, Näsi M, Oksanen A, Räsänen P. (2017). Online Hate and Harmful Content: Cross-National Perspectives. (Routledge Advances in Sociology). Abingdon: Routledge.

Kelly TM, Donovan JE, Chung T, Bukstein OG, Cornelius JR. (2009). Brief screens for detecting alcohol use disorder among 18-20 year old young adults in emergency departments: Comparing AUDIT-C, CRAFFT, RAPS4-QF, FAST, RUFT-Cut, and DSM-IV 2-Item Scale. Addict Behav 34: 668-674.

Knight JR, Sherritt L, Harris SK, Gates EC, Chang G. (2003). Validity of brief alcohol screening tests among adolescents: a comparison of the AUDIT, POSIT, CAGE, and CRAFFT. Alcohol Clin Exp Res 27: 67-73.

Larson R, and Hansen D. (2005). The development of strategic thinking: Learning to impact human systems in a youth activism program. Hum Dev 48: 327-349.

MacKillop J, Anderson EJ, Castelda BA, Mattson RE, Donovick PJ. (2006). Convergent validity of measures of cognitive distortions, impulsivity, and time perspective with pathological gambling. Psychol Addict Behav 20: 75.

McGloin JM. (2009). Delinquency balance: Revisiting peer influence. Criminology, 47: 439-477. McCreanor T, Lyons A, Griffin C, Goodwin I, Moewaka Barnes H, et al. (2013). Youth drinking 
cultures, social networking and alcohol marketing: Implications for public health. Crit Public Health, 23:110-120

McMorris BJ, Catalano RF, Kim MJ, Toumbourou JW, Hemphill SA. (2011). Influence of family factors and supervised alcohol use on adolescent alcohol use and harms: similarities between youth in different alcohol policy contexts. J Stud Alcohol Drugs 72: 418-428.

Meerkerk GJ, Van Den Eijnden RJ, Vermulst AA, Garretsen HF. (2009). The compulsive internet use scale (CIUS): some psychometric properties. Cyberpsychol Behav 12: 1-6.

Mei, S., Yau, Y. H., Chai, J., Guo, J., \& Potenza, M. N. (2016). Problematic Internet use, wellbeing, self-esteem and self-control: Data from a high-school survey in China. Addict Behav 61: 74-79.

de Meneses-Gaya C, Zuardi AW, Loureiro SR, Crippa JAS. (2009). Alcohol Use Disorders identification Test (AUDIT): An updated systematic review of psychometric properties. Psychol Neurosci, 2:83

Minkkinen J, Oksanen A, Näsi M, Keipi T, Kaakinen M, et al. (2016). Does social belonging to primary groups protect young people from the effects of pro-suicide sites? A comparative study of four countries. Crisis: The Journal of Crisis Intervention and Suicide Prevention, 37: 31-41 Moreno MA, Briner LR, Williams A, Brockman L, Walker L, et al. (2010). A content analysis of displayed alcohol references on a social networking web site. J Adolesc Health 47: 168-175

Moreno MA, Whitehill JM. (2014). Influence of social media on alcohol use in adolescents and young adults. Alcohol Res 36: 91-100.

Moreno MA, Kota R, Schoohs S, Whitehill JM. (2013). The Facebook Influence model: A concept mapping approach. Cyberpsychol Behav Soc Netw 16: 504-511

Morioka H, Itani O, Osaki Y, Higuchi S, Jike M, Kaneita Y, ... Ohida T. (2017). The association between alcohol use and problematic internet use: A large-scale nationwide cross-sectional study of adolescents in Japan. J Epidemiol 27: 107-111. 
Murthy D. (2012). Towards a Sociological Understanding of Social Media: Theorizing Twitter. Sociology 46: 1059-1073.

National Institute on Alcohol Abuse and Alcoholism [NIAAA]. (2017). Underage Drinking, NIAAA, viewed 2 May 2019, <https://www.niaaa.nih.gov/publications/brochures-and-factsheets/underage-drinking>

Oeldorf-Hirsch, A., \& Sundar, S. S. (2016). Social and technological motivations for online photo sharing. J Broadcast Electron Media 60:624-642.

Official Statistics of Finland. (2017). The Internet is used ever more commonly with a mobile phone - even for Shopping, OSF, viewed 29 August 2019, https://www.stat.fi/til/sutivi/2018/sutivi_2018_2018-12-04_tie_001_en.html

Oksanen A, Hawdon J, Holkeri E, Näsi M, Räsänen P. (2014). Exposure to online hate among young social media users. Sociol Stud Child Youth 18: 253-273.

Oksanen A, Aaltonen M, Majamaa K, Rantala K. (2017). Debt problems, home-leaving, and boomeranging: A register-based perspective on economic consequences of moving away from parental home. Int J Consum Stud 41: 340-352.

O'Keeffe GS and Clarke-Pearson K. (2011). The impact of social media on children, adolescents, and families. Pediatrics, 127: 800-804.

Pallis G, Zeinalipour-Yazti D, Dikaiakos MD. (2011). Online social networks: Status and trends. In Vakali A and Jain LC (Eds.). New directions in web data management 1 (pp. 213-234). Berlin, Germany: Springer.

Patrick ME and Schulenberg JE. (2014). Prevalence and predictors of adolescent alcohol use and binge drinking in the United States. Alcohol Res 35: 193-200.

Patton DU, Hong JS, Ranney M, Patel S, Kelley C, et al. (2014). Social media as a vector for youth violence: A review of the literature. Comput Human Behav 35: 548-553. 
Pevalin DJ. (2000). Multiple applications of the GHQ-12 in a general population sample: An investigation of long-term retest effects. Soc Psychiatry Psychiatr Epidemiol 35: 508-512

Plant M. (2002). Risk-takers: Alcohol, drugs, sex and youth. Routledge.

Richards D, Caldwell PH, Go H. (2015). Impact of social media on the health of children and young people. J Paediatr Child Health 51: 1152-1157.

Romer D. (2010). Adolescent risk taking, impulsivity, and brain development: Implications for prevention. Dev Psychobiol 52: 263-276

Romer D, Betancourt LM, Brodsky NL, Giannetta JM, Yang W, et al. (2011). Does adolescent risk taking imply weak executive function? A prospective study of relations between working memory performance, impulsivity, and risk taking in early adolescence. Dev Sci 14: 1119-1133

Rosenquist JN, Murabito J, Fowler JH, Christakis NA. (2010). The spread of alcohol consumption behavior in a large social network. Ann Intern Med 152: 426.

Rubinsky AD, Dawson DA, Williams EC, Kivlahan DR, Bradley KA. (2013). AUDIT-C scores as a scaled marker of mean daily drinking, alcohol use disorder severity, and probability of alcohol dependence in a US general population sample of drinkers. Alcohol Clin Exp Res 37: 13801390.

Savimäki T, Kaakinen M, Räsänen P, Oksanen A. (2018). Disquieted by Online Hate: Negative Experiences of Finnish Adolescents and Young Adults. Eur J Crim Pol Res

Slutske WS. (2005). Alcohol use disorders among US college students and their non-collegeattending peers. Arch Gen Psychiatry 62:321-327.

Smith A and Anderson M. (2018). Social Media Use in 2018, Pew Research Center, viewed 30 April 2019, <https://www.pewinternet.org/2018/03/01/social-media-use-in-2018/>

Statista. (2017). Social media usage in Spain, Statista, viewed 30 April 2019 <https://www.statista.com/study/31073/social-media-usage-in-spain-statista-dossier/> 
Statista. (2018a). Internet usage of teenagers in the United States, Statista, viewed 30 April 2019 <https://www.statista.com/study/20944/teenagers-in-the-us-internet-and-online-shoppingstatista-dossier/>

Statista. (2018b). Frequency of using social media among adolescents in South Korea in 2018, Statista, viewed 30 April 2019 <https://www.statista.com/statistics/961361/south-korea-socialmedia-use-frequency-among-adolescents/>

Statista. (2019). Social media usage in Finland. Statista, viewed 30 April 2019, <https://www.statista.com/study/37855/social-media-usage-in-finland-statista-dossier/>

Steers MLN, Neighbors C, Wickham RE, Petit WE, Kerr B, et al. (2019). My friends, I'm\# SOTALLYTOBER: A longitudinal examination of college students' drinking, friends' approval of drinking, and Facebook alcohol-related posts. Digit Health 5: 1-11

Stogner J, Boman IV JH, Lee Miller B. (2015). Assessing the relationship between divergent drinking and perceptions of friendship quality between students. J Child Adolesc Subst Abuse 24: 387396.

Substance Abuse and Mental Health Services Administration [SAMHSA]. (2018). Key substance use and mental health indicators in the United States: Results from the 2017 National Survey on Drug Use and Health (HHS Publication No. SMA 18-5068, NSDUH Series H-53). Rockville, MD: Center for Behavioral Health Statistics and Quality, Substance Abuse and Mental Health Services Administration, viewed 2 May 2019, <https:/www.samhsa.gov/data/>

Van den Eijnden RJ, Meerkerk GJ, Vermulst AA, Spijkerman R, Engels RC. (2008). Online communication, compulsive Internet use, and psychosocial well-being among adolescents: A longitudinal study. Dev Psychol, 44: 655

Werneke U, Goldberg DP, Yalcin I, Üstün BT. (2000). The stability of the factor structure of the General Health Questionnaire. Psychol Med 30: 823-829.

Whittaker E and Kowalski RM. (2015). Cyberbullying via social media. J Sch Violence 14: 11-29 
Winpenny EM, Marteau TM, Nolte E. (2013). Exposure of children and adolescents to alcohol marketing on social media websites. Alcohol Alcohol 49: 154-159.

World Health Organization. (2010). Global Strategy to reduce the harmful use of alcohol, WHO, $\begin{array}{llll}\text { viewed } & 28 & \text { April } & 2019\end{array}$ $<$ https://www.who.int/substance_abuse/publications/global_strategy_reduce_harmful_use_alc ohol/en/>

Wu AM, Cheung VI, Ku L, Hung EP. (2013). Psychological risk factors of addiction to social networking sites among Chinese smartphone users. J Behav Addict 2: 160-166.

Ybarra ML and Mitchell KJ. (2008). How risky are social networking sites? A comparison of places online where youth sexual solicitation and harassment occurs. Pediatrics, 121: e350-e357.

Yoo W, Paek HJ, Hove T. (2018). Differential Effects of Content-Oriented Versus User-Oriented Social Media on Risk Perceptions and Behavioral Intentions. Health Commun 1-11. 
Table 1. Descriptive statistics

\begin{tabular}{|c|c|c|c|c|c|c|c|c|c|c|c|c|}
\hline & & $\begin{array}{l}\text { United } \\
\text { States }\end{array}$ & & & $\begin{array}{l}\text { South } \\
\text { Korea }\end{array}$ & & & Finland & & & Spain & \\
\hline Variable & $M$ & $S D$ & Range & $M$ & $S D$ & Range & $M$ & $S D$ & Range & $M$ & $S D$ & Range \\
\hline AUDIT-C & 1.80 & 2.30 & $0-12$ & 3.20 & 3.15 & $0-12$ & 3.36 & 2.69 & $0-12$ & 2.29 & 2.17 & $0-12$ \\
\hline $\begin{array}{l}\text { Daily Social Media } \\
\text { use }\end{array}$ & 1.52 & 1.41 & $0-5$ & 2.18 & 1.42 & $0-5$ & 1.84 & 1.26 & $0-5$ & 2.18 & 1.42 & $0-5$ \\
\hline Offline belonging & 20.33 & 6.70 & $3-30$ & 21.33 & 5.82 & $3-30$ & 20.19 & 6.14 & $3-30$ & 21.34 & 5.81 & $3-30$ \\
\hline CIUS & 21.72 & 13.54 & $0-56$ & 22.13 & 12.63 & $0-56$ & 18.79 & 11.13 & $0-56$ & 22.17 & 12.66 & $0-56$ \\
\hline GHQ-12 & 13.48 & 6.75 & $0-36$ & 13.92 & 6.45 & $0-36$ & 14.15 & 6.34 & $0-36$ & 13.92 & 6.44 & $0-36$ \\
\hline Impulsivity & 2.55 & 1.42 & $0-5$ & 2.68 & 1.34 & $0-5$ & 2.64 & 1.46 & $0-5$ & 2.68 & 1.34 & $0-5$ \\
\hline Risk-taking & 5.74 & 2.30 & $1-10$ & 5.40 & 2.28 & $1-10$ & 5.12 & 2.28 & $1-10$ & 5.40 & 2.28 & $1-10$ \\
\hline Age & 20.05 & 3.19 & $15-25$ & 20.61 & 3.24 & $15-25$ & 21.29 & 2.85 & $15-25$ & 20.07 & 3.16 & $15-25$ \\
\hline Cat. variables & coding & $n$ & $\%$ & coding & $n$ & $\%$ & coding & $n$ & $\%$ & coding & $n$ & $\%$ \\
\hline \multirow[t]{2}{*}{ Gender } & male & 604 & 49.83 & male & 591 & 49.58 & male & 600 & 50 & male & 621 & 51.24 \\
\hline & female & 608 & 50.17 & female & 601 & 50.42 & female & 600 & 50 & female & 591 & 48.76 \\
\hline Daily Facebook & Yes & 448 & 36.96 & Yes & 254 & 21.10 & Yes & 490 & 40.83 & Yes & 255 & 21.04 \\
\hline Daily YouTube & Yes & 445 & 36.72 & Yes & 549 & 45.60 & Yes & 435 & 36.25 & Yes & 552 & 45.54 \\
\hline Daily Twitter & Yes & 206 & 17.00 & Yes & 249 & 20.68 & Yes & 90 & 7.50 & Yes & 251 & 20.71 \\
\hline Daily Instagram & Yes & 372 & 30.69 & Yes & 698 & 57.97 & Yes & 388 & 32.33 & Yes & 702 & 57.92 \\
\hline Daily Instant msg. & Yes & 381 & 31.44 & Yes & 877 & 72.84 & Yes & 800 & 66.67 & Yes & 882 & 72.77 \\
\hline Upload pictures & Yes & 362 & 29.87 & Yes & 350 & 29.07 & Yes & 115 & 9.58 & Yes & 355 & 29.29 \\
\hline
\end{tabular}

Note. AUDIT-C = Alcohol Use Disorders Identification Test, CIUS = Compulsive Internet use -scale, GHQ-12= General Health Questionnaire. Daily Instant msg.

$=$ Daily Instant messaging. 
Table 2. Direct regression effects predicting hazardous alcohol use based on social media type in four countries

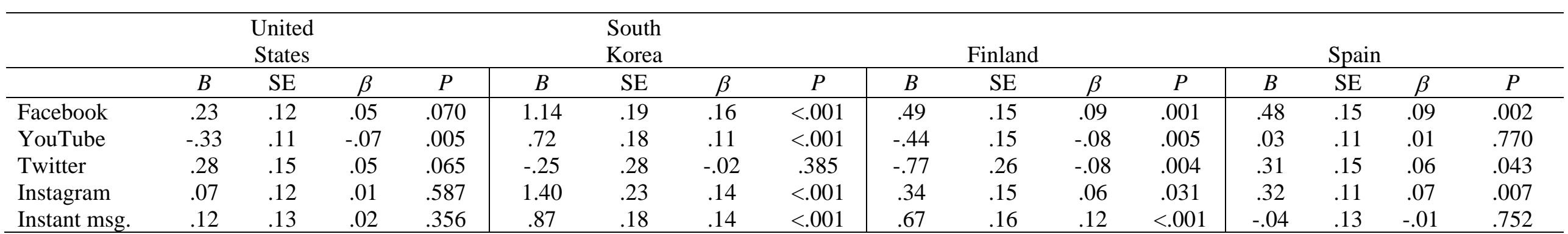

Note. Effects calculated separately for each social media. All the regression models were adjusted by compulsive Internet use, offline belonging, psychological distress,

impulsivity, risk-taking, age, and gender. Instant msg. = Instant messaging; $B=$ unstandardized regression weights; $\beta=$ standardized beta coefficient. 
Figure 1. Mediation effects between daily Facebook use, daily Instagram use, and hazardous alcohol use via uploading pictures to social media in the U.S. and Spain

\section{U.S.}

Uploading Pictures

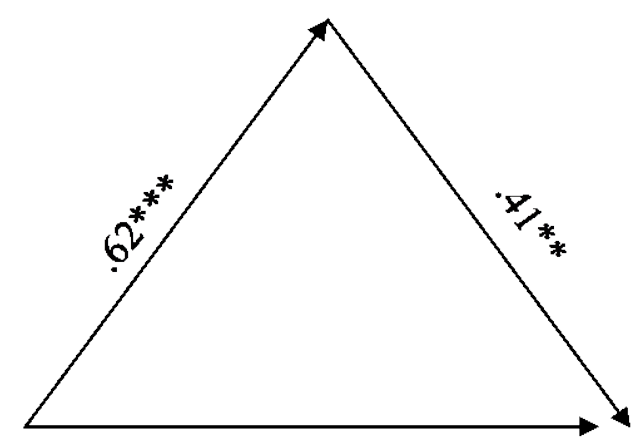

Daily Facebook use $\quad .17(.23) \quad$ Hazardous alcohol use

Uploading Pictures

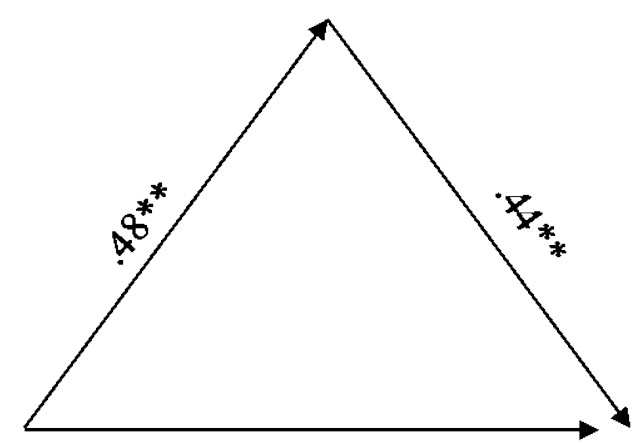

Daily Instagram use $.03(.07)$ Hazardous alcohol use

\section{SPAIN}

Uploading Pictures

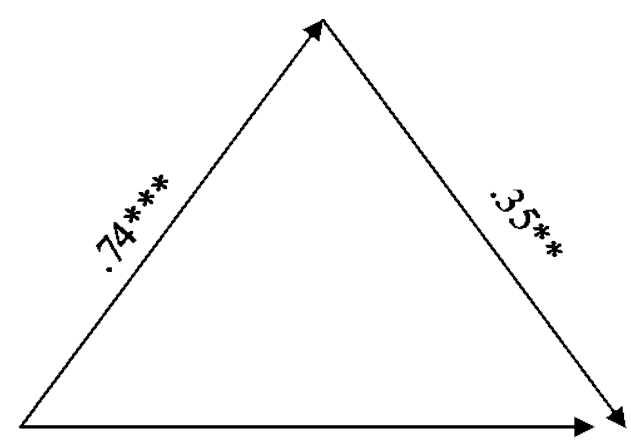

Daily Facebook use $.43^{* *}\left(.48^{* *}\right) \quad$ Hazardous alcohol use

Uploading Pictures

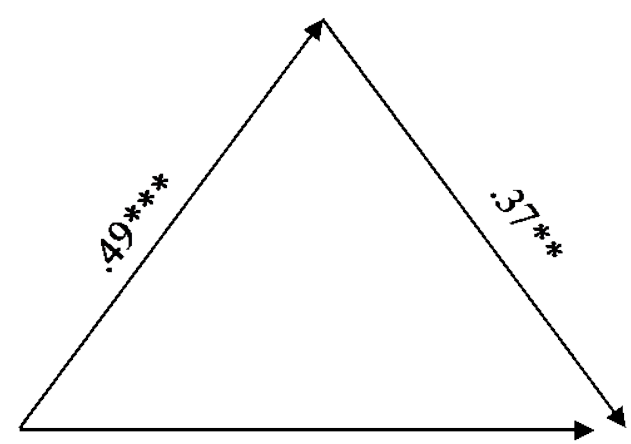

Daily Instagram use $.28^{*}\left(.32^{* *}\right)$ Hazardous alcohol use 
Appendix

Table 3. Logistic regression effects predicting hazardous alcohol use based on social media type in four countries

\begin{tabular}{|c|c|c|c|c|c|c|c|c|c|c|c|c|c|c|c|c|}
\hline & & $\begin{array}{l}\text { Unite } \\
\text { States }\end{array}$ & & & & $\begin{array}{l}\text { South } \\
\text { Kore }\end{array}$ & & & & inlan & & & & Spain & & \\
\hline & $B$ & $\mathrm{SE}$ & OR & $P$ & $B$ & $\mathrm{SE}$ & OR & $P$ & $B$ & $\mathrm{SE}$ & OR & $P$ & $B$ & $\mathrm{SE}$ & OR & $P$ \\
\hline Facebook & .22 & .15 & 1.2 & .140 & .66 & .14 & 1.9 & $<.001$ & .52 & .13 & 1.7 & $<.001$ & .36 & .17 & 1.4 & .036 \\
\hline YouTube & -.40 & .15 & .67 & .007 & .49 & .13 & 1.6 & $<.001$ & -.40 & .13 & .67 & .003 & .11 & .14 & 1.1 & .440 \\
\hline Twitter & .18 & .17 & 1.2 & .336 & -.37 & .23 & .70 & .106 & -.65 & .25 & .52 & .009 & .32 & .17 & 1.4 & .054 \\
\hline Instagram & .07 & .15 & 1.1 & .641 & .57 & .17 & 1.8 & .001 & .33 & .14 & 1.4 & .014 & .29 & .15 & 1.3 & .051 \\
\hline Instant msg. & .08 & .15 & 1.1 & .597 & .53 & .13 & 1.7 & $<.001$ & .58 & .14 & 1.8 & $<.001$ & -.28 & -.16 & .76 & .752 \\
\hline
\end{tabular}

Note. Effects calculated separately for each social media. All the regression models were adjusted by compulsive Internet use, offline belonging, psychological distress, impulsivity, risk-taking, age, and gender. Instant msg. = Instant messaging; $B=$ unstandardized regression weights; $\beta=$ standardized beta coefficient. 